\title{
LAPAROSCOPIC TOTALLY EXTRAPERITONEAL (TEP) REPAIR VERSUS LICHTENSTEIN'S REPAIR FOR INGUINAL HERNIA- A PROSPECTIVE STUDY
}

\author{
Chandra Shekhar'1, Shadab Asif², Osman Musa Hingora ${ }^{3}$
}

${ }^{1}$ Assistant Professor, Department of General Surgery, Era's Lucknow Medical College, Lucknow, Uttar Pradesh. ${ }^{2}$ Assistant Professor, Department of General Surgery, Era's Lucknow Medical College, Lucknow, Uttar Pradesh. 3Professor, Department of General Surgery, Era's Lucknow Medical College, Lucknow, Uttar Pradesh.

ABSTRACT
BACKGROUND
Hernia repair is one of the common general surgical operations. Open mesh repair method (Lichtenstein's repair) is known as
"Gold Standard" for inguinal hernia. Slowly another technique Total Extra-Peritoneal (TEP) repair emerged. TEP repair is
considered to be an "advanced" laparoscopic procedure and still not available widely.

\section{MATERIALS AND METHODS}

Our study compared outcomes of laparoscopic inguinal hernia repair with open mesh hernia repair. Total of 75 patients in each group included in study.

\section{RESULTS}

The mean age of patients presenting with hernia was 36.96 years and 37.08 years, while mean weight was $58.4 \mathrm{~kg}$ and $61.56 \mathrm{~kg}$ for laparoscopic and open group respectively with age ranged from 21 to 55 years. Mean operative time was 90 minutes (Unilateral), 117 minutes (Bilateral) and 70 minutes for laparoscopic and open mesh hernioplasty respectively. Analgesic dose required for laparoscopic group and open group was 3.58 and 3.16 respectively. The cost of surgery in laparoscopic group was $11000-14000$ Rs. (Mean- 12,000 Rs.), while in open group was 6000 - 8500 Rs. (Mean- 7000 Rs.).

\section{CONCLUSION}

Although laparoscopic totally extraperitoneal hernia repair has many advantages over open mesh repair, but when it comes to availability of the technical expertise, operative time, cost of surgery, open hernioplasty seems better.

\section{KEYWORDS}

Laparoscopic Totally Extraperitoneal (TEP) Repair, Inguinal Hernia, Lichtenstein's Repair, Local Anaesthesia.

HOW TO CITE THIS ARTICLE: Shekhar C, Asif S, Hingora OM. Laparoscopic totally extraperitoneal (TEP) repair versus Lichtenstein's repair for inguinal hernia- a prospective study. J. Evolution Med. Dent. Sci. 2017;6(25):2065-2068, DOI: $10.14260 /$ Jemds/2017/449

\section{BACKGROUND}

Hernia is a protrusion of a viscous or part of it through an opening or weakness in the wall of its containing cavity. Inguinal hernia repair is one of common general surgical operations.[1] Practice of tissue-based hernia repair has decreased due to routine use of prosthetic mesh during hernia repair resulting in a risk reduction of recurrence of between 50 to $75 \% .^{[2]}$ Open mesh repair method (Lichtenstein's repair) is known as "Gold Standard."[3] Inguinal hernias have been treated traditionally with open methods of herniorrhaphy or hernioplasty, but the trends have changed in the last decade with the introduction of minimal access surgery. Laparoscopic inguinal hernia repair has been introduced after the success of laparoscopic cholecystectomy on the premise that there would be less postoperative discomfort and pain, the repair of recurrent hernias would be easier and bilateral hernia could be treated concurrently with improved cosmesis. ${ }^{[4]}$ Ger first reported

Financial or Other, Competing Interest: None.

Submission 19-09-2016, Peer Review 22-12-2016,

Acceptance 29-12-2016, Published 27-03-2017.

Corresponding Author:

Dr. Chandra Shekhar,

House No. 1898 E Block, Rajajipuram,

Lucknow-206017, Uttar Pradesh.

E-mail: csr13582@gmail.com

DOI: $10.14260 /$ jemds $/ 2017 / 449$ laparoscopic inguinal hernia repair.[5] The first method used for this had been the transabdominal pre-peritoneal (TAPP) approach, but issues such as violation of the peritoneal cavity and occurrence of several complications, e.g. intestinal obstruction and subsequent to entry of the peritoneal cavity had always been a concern for this approach.[3] Slowly laparoscopic totally extraperitoneal (TEP) repair became widely used. TEP repair is still considered to be an "advanced" laparoscopic procedure, because of the unfamiliar anatomy and requires considerable training and experience.[6] Techniques vary essentially by using a mesh or not, the position of the mesh (onlay, inlay or sublay), the approach of the hernia (anterior or posterior) and the technique being open or endoscopic. It has been shown that the use of a mesh is associated with a reduced number of patients with recurrence. ${ }^{[7]}$ Our study compared outcomes of laparoscopic totally extraperitoneal repair with Lichtenstein's repair.

\section{MATERIALS AND METHODS}

This prospective study was done in patients presenting to General Surgery OPD from January 2011 to December 2015 at Era Medical College, Lucknow. Total of 75 patients in each group included in study.

\section{Inclusion Criteria}

Patients aged > 20 years who had unilateral or bilateral reducible, uncomplicated inguinal hernia with no 
contraindications for general or local anaesthesia were selected.

\section{Exclusion Criteria}

Women, patients with irreducible, strangulated, obstructed hernia, recurrent hernia, deranged coagulation, spinal deformity. TEP converted cases were also excluded.

Details of operative procedure and deferent per and postoperative parameters (Vide infra) recorded on the predesigned proforma. Laparoscopic repair and open mesh hernioplasty were performed under general and local anaesthesia (Plain 2\% Xylocaine) respectively.

Prophylactic antibiotic (Ceftriaxone) was administered intravenously at the time of induction of anaesthesia and continued for 3 days postoperatively. Preoperatively, we discussed and explained in detail to all patients about postoperative pain charting, Visual Analogue Scale (VAS), Pain scoring chart. The Y-axis of the VAS score is numbered from zero to ten at one centimetre interval. The 10 number denotes the worst imaginable pain, while zero denotes no pain in resting state. The X-axis of the scale is numbered as 6 hrs., 12 hrs., 24 hrs., 3 days and 7 days to record the postoperative pain at these times. We compared laparoscopic repair outcome with available data.

\section{Laparoscopic Totally Extraperitoneal Repair (TEP)}

All patients were operated in supine position with $15-20$ degrees Trendelenburg's position. Initial $10 \mathrm{~mm}$ subumbilical trocar was introduced by technique described by McKernan.(8) After insufflation of $\mathrm{CO} 2$ in pre-peritoneal space remaining two $5 \mathrm{~mm}$ trocars were placed (Lowest at $2-3 \mathrm{~cm}$ above the pubic symphysis and third one in between subumbilical and lowest port) under direct camera vision. Direct/indirect hernia sac was completely reduced, while in some patients it needed division. In cases with direct hernia, cord structures were explored for any synchronous indirect sac or peritoneal sleeve, which if it was present reduced; $10 \mathrm{x}$ $15 \mathrm{~cm}$ polypropylene mesh introduced via $10 \mathrm{~mm}$ subumbilical port and after unrolling fixed to rectus muscle and cooper ligament using tackers, while no fixation done laterally. Anterior rectus sheath and skin were closed by Vicryl 1-0 and Nylon 2-0 respectively.

\section{Open Mesh Repair (Lichtenstein's Repair)}

Approximately, 7 - $8 \mathrm{~cm}$ long oblique incision was placed 1 - 2 $\mathrm{cm}$ above and parallel to inguinal ligament starting from pubic tubercle and extending laterally up to the midinguinal point. Dissection done until external oblique aponeurosis reached, which was divided in line of its fibres to explore the inguinal canal. Upper and lower external oblique flaps are created to accommodate mesh. Cremasteric fascia and muscle were divided along the whole length to expose the hernia sac. Indirect hernia sac separated till deep ring, then excised while direct sac either invaginated using Vicryl 2-0 or was excised if large.

Transversalis fascia strengthened by placing polypropylene mesh $(15 \times 8 \mathrm{~cm})$ and fixed as described in Lichtenstein's repair technique. Care was taken that mesh should be lax, slightly wrinkled rather flat to avoid tension. It was ensured that medially mesh should lay approx. $2 \mathrm{~cm}$ medial to pubic tubercle, upper margin should be approximately 3 to $4 \mathrm{~cm}$ above the Hesselbach's triangle and $3 \mathrm{~cm}$ lateral to deep inguinal ring.

\section{Post-Operative Observation}

All patients were looked for any bleeding, haematoma formation, urinary retention, subcutaneous emphysema or scrotal oedema in the evening following surgery. Intravenous antibiotic was given and pain was managed by giving intravenous $75 \mathrm{mg}$ Diclofenac sodium.

Duration of stay was defined as days spent postoperatively and while return to work was defined by walking, bathing and small household work. Patients were followed at 6 weeks, 3 months, 6 months and 1 year postoperatively. On every visit patient was examined properly, analgesic requirement noted.

\section{Statistical Analysis}

All data compiled on Microsoft Excel computer program and appropriate statistical analysis done. Descriptive data and their distribution were analysed by non-parametric test; Fischer exact chi square test (test of significance comparing qualitative or nominal and ordinal variable) and quantitative data analysed using the paired student's t-test.

\section{RESULTS}

The mean age of patients presenting with hernia was 36.96 years and 37.08 years, while mean weight was $58.4 \mathrm{~kg}$ and $61.56 \mathrm{~kg}$ for laparoscopic and open group respectively with age range from 21 to 55 years. Maximum patients belonged to age group 41 - 45 years in both laparoscopic and open group which was statistically insignificant in both groups of the patients. There were $24(32 \%)$ and $0(0 \%)$ bilateral hernia in laparoscopic and open group respectively, 39 (52\%) and 51 (68\%) unilateral right in laparoscopic and open group respectively and $12(16 \%)$ and 24 (32\%) unilateral left hernia in laparoscopic and open group respectively; 30 (40\%) and 48 (64\%) direct hernia, 45 (60\%) and 27 (36\%) indirect hernia in laparoscopic and open group respectively. Mean operative time was 90 minutes (Unilateral), 117 minutes (Bilateral) and 70 minutes for laparoscopic and open mesh hernioplasty respectively. The incidence of haematoma in Laparoscopic group was $2(2.6 \%)$ and in open group was 5 (6.6\%); neuralgia was present in $1(1.3 \%)$ in laparoscopic and $3(4 \%)$ in open group; seroma was present in $3(4 \%)$ in laparoscopic group and $0 \%$ in open group; wound infection was present in $3(4 \%)$ cases of each group. Analgesic dose required for laparoscopic group and open group was 3.58 and 3.16 respectively. Pain score significantly lower in open group at $6 \mathrm{hrs}$. and $12 \mathrm{hrs}$. and very significantly lower at 24 hours. While in laparoscopic Group significantly lower on 3 days and 7 days.

We called all the patients to attend surgical OPD between $2^{\text {nd }}$ and $3^{\text {rd }}$ week after surgery for suture removal. There were no recurrences in either group after 1 year followup.

\begin{tabular}{|c|c|}
\hline Group & Number \\
\hline Laparoscopic & 75 \\
\hline Open & 75 \\
\hline Total & $\mathbf{1 5 0}$ \\
\hline Distribution of Patients in Two Groups \\
\hline
\end{tabular}




\begin{tabular}{|c|c|c|c|c|}
\hline \multirow{2}{*}{$\begin{array}{c}\text { Age } \\
\text { Group }\end{array}$} & Laparoscopic & \multicolumn{2}{c|}{ Open } \\
\cline { 2 - 5 } & Number & $\mathbf{\%}$ & Number & $\mathbf{\%}$ \\
\hline $21-25$ & 12 & 16 & 12 & 16 \\
\hline $26-30$ & 15 & 20 & 12 & 16 \\
\hline $31-35$ & 12 & 16 & 12 & 16 \\
\hline $36-40$ & 9 & 12 & 12 & 16 \\
\hline $41-45$ & 15 & 20 & 15 & 20 \\
\hline $46-50$ & 3 & 4 & 12 & 1 \\
\hline $51-55$ & 9 & 12 & 9 & 12 \\
\hline Total & $\mathbf{7 5}$ & $\mathbf{1 0 0}$ & $\mathbf{7 5}$ & $\mathbf{1 0 0}$ \\
\hline \multicolumn{5}{|c|}{ Distribution of Age } \\
\hline
\end{tabular}

\begin{tabular}{|c|c|c|}
\hline Complication & Laparoscopic & Open \\
\hline Haematoma & $2(2.6 \%)$ & $5(6.6 \%)$ \\
\hline Neuralgia & $1(1.3 \%)$ & $3(4 \%)$ \\
\hline Seroma & $3(4 \%)$ & 0 \\
\hline Wound infection & $3(4 \%)$ & $3(4 \%)$ \\
\hline Vascular injury & $1(1.3 \%)$ & 0 \\
\hline \multicolumn{2}{|c|}{ Post-Operative Complication } \\
\hline
\end{tabular}

$\mathrm{P}=1.00$ (Fischer exact chi-square test)

\begin{tabular}{|c|c|c|}
\hline \multirow{2}{*}{ Mean Age (Yrs.) } & Laparoscopic & Open \\
\cline { 2 - 3 } & 36.96 & 37.08 \\
\hline SD & 9.98 & 9.67 \\
\hline Range & $22-55$ & $22-54$ \\
\hline \multicolumn{2}{|r|}{ Mean Age Distribution } \\
\hline
\end{tabular}

\begin{tabular}{|c|c|c|}
\hline \multirow{2}{*}{ Mean Weight $(\mathrm{kg})$} & Laparoscopic & Open \\
\cline { 2 - 3 } & 58.4 & 61.56 \\
\hline SD & 6.9 & 5.51 \\
\hline Range & $46-72$ & $50-72$ \\
\hline \multicolumn{2}{|c|}{ Mean Weight Distribution } \\
\hline
\end{tabular}

$\mathrm{P}=0.966$ (Student $\mathrm{t}$-test)

\begin{tabular}{|c|c|c|c|c|}
\hline \multirow{2}{*}{$\begin{array}{c}\text { Weight } \\
(\mathbf{k g})\end{array}$} & \multicolumn{2}{|c|}{ Laparoscopic } & \multicolumn{2}{c|}{ Open } \\
\cline { 2 - 5 } & Number & $\mathbf{\%}$ & Number & $\mathbf{\%}$ \\
\hline $46-50$ & 12 & 16 & 3 & 4 \\
\hline $51-55$ & 18 & 24 & 9 & 12 \\
\hline $56-60$ & 12 & 16 & 24 & 32 \\
\hline $61-65$ & 24 & 32 & 21 & 28 \\
\hline $66-70$ & 6 & 8 & 15 & 20 \\
\hline $71-55$ & 3 & 4 & 3 & 4 \\
\hline Total & $\mathbf{7 5}$ & $\mathbf{1 0 0}$ & $\mathbf{7 5}$ & $\mathbf{1 0 0}$ \\
\hline \multicolumn{6}{|c|}{ Weight Distribution } \\
\hline
\end{tabular}

$\mathrm{P}=0.360$ (Fischer exact chi-square test)

\begin{tabular}{|c|c|c|c|c|}
\hline \multirow{2}{*}{ Side } & \multicolumn{2}{|c|}{ Laparoscopic } & \multicolumn{2}{c|}{ Open } \\
\cline { 2 - 5 } & Number & $\mathbf{\%}$ & Number & $\mathbf{\%}$ \\
\hline Right & 39 & 52 & 51 & 68 \\
\hline Left & 12 & 16 & 24 & 32 \\
\hline Bilateral & 24 & 32 & 0 & 0 \\
\hline Total & $\mathbf{7 5}$ & $\mathbf{1 0 0}$ & $\mathbf{7 5}$ & $\mathbf{1 0 0}$ \\
\hline \multicolumn{5}{|c|}{ Distribution according to Side } \\
\hline
\end{tabular}

\begin{tabular}{|c|c|c|c|c|}
\hline \multirow{2}{*}{ Type } & \multicolumn{2}{|c|}{ Laparoscopic } & \multicolumn{2}{c|}{ Open } \\
\cline { 2 - 5 } & Number & $\mathbf{\%}$ & Number & $\mathbf{\%}$ \\
\hline Direct & 30 & 40 & 48 & 64 \\
\hline Indirect & 45 & 60 & 27 & 36 \\
\hline Total & $\mathbf{7 5}$ & $\mathbf{1 0 0}$ & $\mathbf{7 5}$ & $\mathbf{1 0 0}$ \\
\hline \multicolumn{4}{|c}{ Distribution according to type } \\
\hline
\end{tabular}

\begin{tabular}{|c|c|c|}
\hline $\begin{array}{c}\text { Operative Time } \\
\text { (Min) }\end{array}$ & Laparoscopic & Open \\
\hline Mean & 90,117 & 70 \\
\hline SD & 24 & 22 \\
\hline Range & $55-84$ & $30-68$ \\
\hline \multicolumn{2}{|c|}{ Comparison of Operative Time } \\
\hline
\end{tabular}

$\mathrm{P}=0.00$ (Fischer exact chi square test)

\begin{tabular}{|c|c|c|c|c|c|c|}
\hline \multirow{2}{*}{ Time } & \multicolumn{3}{|c|}{ Laparoscopic } & \multicolumn{3}{c|}{ Open } \\
\cline { 2 - 7 } & Mean & SD & Range & Mean & SD & Range \\
\hline 6 hrs. $^{*}$ & 2.29 & 2.69 & $0-8$ & - & - & - \\
\hline 12 hrs. $^{* *}$ & 2.54 & 2.3 & $0-7$ & 1.96 & 1.21 & $0-6$ \\
\hline 24 hrs. $^{* * *}$ & 2.79 & 1.74 & $0-6$ & 1.28 & 0.89 & $0-4$ \\
\hline 3 days.*** & 1.25 & 1.39 & $0-6$ & 0.36 & 0.70 & $0-2$ \\
\hline 7 days**** & 0.42 & 0.65 & $0-2$ & 0.28 & 0.54 & $0-2$ \\
\hline \multicolumn{6}{|c|}{ Comparison of Post-Operative VAS Scores } \\
\hline
\end{tabular}

${ }^{*} \mathrm{p}=0.359,{ }^{*} \mathrm{p}=0.279,{ }^{* * *} \mathrm{p}=0.001,{ }^{* * * *} \mathrm{p}=0.008,{ }^{* * * * *} \mathrm{p}=$ 0.429 student t-test

\begin{tabular}{|c|c|c|}
\hline Dose & Laparoscopic & Open \\
\hline Mean & 3.58 & 3.16 \\
\hline SD & 2.06 & 2.27 \\
\hline Range & $1-9$ & $0-9$ \\
\hline \multicolumn{2}{|c|}{ Comparison of Analgesic Doses } \\
\hline
\end{tabular}

$\mathrm{P}=0.498$ (Student $\mathrm{t}$-test)

\begin{tabular}{|c|c|c|}
\hline \multirow{2}{*}{ Mean (Days) } & Laparoscopic & Open \\
\cline { 2 - 3 } & 7.77 & 9.46 \\
\hline SD & 1.43 & 1.90 \\
\hline Range (Days) & $5-11$ & $8-15$ \\
\hline \multicolumn{2}{|c|}{ Return to Work (In Days) } \\
\hline
\end{tabular}

\begin{tabular}{|c|c|c|}
\hline \multirow{2}{*}{ Mean } & Laparoscopic & Open \\
\cline { 2 - 3 } & 2.05 days & 2.35 days \\
\hline SD & 0.2 days & 0.20 days \\
\hline Range & $1-3$ days & $1-3$ days \\
\hline \multicolumn{2}{|c|}{ Comparison of Hospital Stay } \\
\hline
\end{tabular}

\begin{tabular}{|c|c|c|}
\hline \multirow{2}{*}{ Mean (In rupees) } & Laparoscopic & Open \\
\cline { 2 - 3 } & 12000 & 7000 \\
\hline Range & $11000-14000$ & $6000-8500$ \\
\hline \multicolumn{3}{|c|}{ Cost of Surgery } \\
\hline
\end{tabular}

\section{DISCUSSION}

Patients were randomised into two groups. Group 1 was operated by laparoscopic totally extraperitoneal repair, while Group 2 by open mesh hernioplasty (Lichtenstein's repair).

The mean age of the patients in Group 1 was 36.96 years $(\mathrm{SD}=9.98)$ and Group 2 was 37.08 yrs. (SD=9.67). The mean weight of patients in Group 1 was $58.4 \mathrm{~kg}(\mathrm{SD}=6.9)$ and in Group 2 was $61.56 \mathrm{~kg}(\mathrm{SD}=5.51)$. Out of total 75 patients included in the Group 139 (52\%) were found to have right, 12 (16\%) had left and 24 (32\%) had bilateral inguinal hernia based on preoperative examination. In Group 251 (68\%) patients had right, 24 (32\%) had left and none had a preoperative diagnosis of bilateral inguinal hernia. Six and 12 patients with preoperative diagnosis of right and left sided hernia respectively had occult contralateral hernia intraoperatively. This is in accord with study conducted by Koehler et al that says overall patients presenting with a preoperative diagnosis of left-sided hernia had increased incidence of occult contralateral hernia than those presenting with right-sided hernia.(9) Rourke et al also found that 
patients with a preoperative diagnosis of left inguinal hernia were 10.5 times more likely to have occult contralateral hernia than are preoperative diagnosis of right inguinal hernia.(10) This association is likely to be attributed to the embryological development of processus vaginalis and timing of the testicular descent. During the embryological development, it is the left testis that descends first and subsequent obliteration of processus vaginalis. A patent processus vaginalis on the right side contributes to the development and manifestation of the occult contralateral hernia in later years.

Forty percent $(n=30)$ of cases on preoperative examination had a direct inguinal hernia and $60 \%(n=45)$ had an indirect hernia in Group 1, amongst Group 2 64\% (n= 48) had a direct inguinal hernia and $36 \%(n=27)$ had an indirect inguinal hernia on preoperative examination.

Mean operative time for Group 1 was found to be 90 minutes and for Group 2 was 70 minutes. The mean operative time was more in the Group 1 in our study as compared to other studies which may be attributed to various factors including the technical setup, lateralisation of cord structures, placement of mesh covering wider area, early learning stage of the surgeon. In one case of laparoscopic group was intraoperative injury of inferior epigastric vessels during dissection, which was controlled by using electrocautery.

In our study, haematoma was present in $2.6 \%$ in Laparoscopic group against $11 \%$ in study conducted by Knook et al,(11) while in open mesh repair haematoma was present in $6.6 \%$ patients. Inguinoscrotal neuralgia was developed postoperatively in $1(1.3 \%)$ and $3(4 \%)$ patients in laparoscopic and open group respectively and were managed conservatively by analgesics and hot fomentation. This was lowest as compared to results of series of Knook et al (2\%), Hourlay et al (1.1\%).(11,12)

Pain can be ascribed to the cutaneous nerve injury during surgery or because mesh impinging on lateral cutaneous nerves of thigh. One $(1.3 \%)$ patient of post-operative neuralgia during laparoscopic repair in our study may be due to placement of tackers a little above the ileopubic tract and avoiding the use of more than two tackers. Seroma was recorded in 3 (4\%) cases in Group 1 and $0 \%$ in Group 2 of our study as compared to figures reported by Schwab et al $(0.07 \%)$, Knook et al (1\%) and Sarli et al (10\%).(13,11,14) These patients had large scrotal hernia and hence needed more dissection, which can explain seroma formation in these patients. In our study, pain was found to be significantly higher in an increased number of bilateral hernia repairs $(12 \%)$ postoperatively as compared to study by Schwab et al (0.9\%). ${ }^{(13)}$

An evaluation of postoperative VAS score showed that scores for bilateral repairs were found to be higher at 6 hours, 12 hours and 24 hours, whereas lower at 3 days and 7 days postoperatively. This is comparable to Sarli et al (mean VAS score ranging from 2 to 4), whereas Topar and Hourlay did not find any significant difference, while in other studies VAS scoring was not used for post-operative pain evaluation. ${ }^{(14,12)}$ Number of analgesic doses required found to be significantly higher in open inguinal hernia repair group at 3.25. This is comparable to that of Schwab et al and higher than in Sarli et al (0.9).(13,14) Patient's perception of pain is multifactorial. The higher figure in our study can be explained by the fact that VAS score was used to evaluate pain, which is a subjective parameter.

Mean hospital stay after surgery was 2.05 days and 2.35 days; mean time to return to work 7.77 days and 9.46 days in Laparoscopic and Open group respectively. The cost of surgery in laparoscopic group was 11000 - 14000 Rs. (Mean12000 Rs.), while in open group was 6000 - 8500 Rs. (Mean7000 Rs.).

\section{CONCLUSION}

Although, laparoscopic repair has many advantages over open mesh hernioplasty in terms of better cosmesis, shorter hospital stay and early return to work, but when it comes to availability of the technical expertise, operative time, cost of surgery open hernioplasty seems better.

\section{REFERENCES}

[1] Mccormack K, Wake B, Perez J, et al. Laparoscopic surgery for inguinal hernia repair: systematic review of effectiveness and economic evaluation. Health Technol Assess 2005;9(14):1-203.

[2] Nyhus LM, Klein MS, Rogers FB. Inguinal hernia. Curr problem surg 1991;28(6):401-50.

[3] Read RC. Recent advances in the repair of groin herniation. Curr problem surg 2003;40(1):13-79.

[4] Schultz LS, Graber JN, Pietrafitta J, et al. Early results with laparoscopic inguinal herniorrhaphy are promising. Clin Laser Mon 1990;8(7):103-5.

[5] Ger R. Laparoscopic hernia operation. Chirurg 1991;62(4):266-70.

[6] Misra MC, Bansal VK, Kumar S, et al. Total extraperitoneal repair of groin hernia: prospective evaluation at a tertiary care centre. Hernia 2008;12(1):65-71.

[7] McCormack K, Scott NW, Go PM, et al. Laparoscopic techniques versus open techniques for inguinal hernia repair. Cochrane Database Syst Rev 2003; 1: CD001785.

[8] Mckernan JB, Laws HL. Laparoscopic repair of inguinal hernia using a totally extraperitoneal prosthetic approach. Surg Endosc 1993;7(1):26-8.

[9] Koehler RH. Diagnosing the occult contralateral inguinal hernia. Surg Endosc 2002;16(3):512-20.

[10] Rourke AO, Zell JA, Varkey-Zell TT, et al. Laparoscopic diagnosis and repair of asymptomatic bilateral inguinal hernia. Am J Surg 2002;183(1):15-9.

[11] Knook MT, Weidema WF, Stassen LP, et al. Endoscopic totally extra peritoneal repair of bilateral inguinal hernias. Br J Surg 1999;86(10):1312-6.

[12] Hourlay P, Topar B. Totally preperitoneal endoscopic inguinal hernia repair. Br j Surg 1997;84(1):61-3.

[13] Schwab JR, Beaired DA, Ramshaw BJ, et al. After 10 years and 1903 inguinal hernias, what is the outcome for laparoscopic repair. Surg endosc 2002;16(8): 1201-6.

[14] Sarli, Lusco DR, Sansebastiano G, et al. Simultaneous repair of bilateral inguinal hernias: a prospective, randomized study of open, tension-free versus laparoscopic approach. Surgery laparoscopy, endoscopy and percutaneous technique 2001;11(4): 262-7. 